\title{
Evaluation of Laparoscopic Ventral Rectopexy for Treatment of Rectal Prolapse
}

\author{
Emad Abdellatif Daoud, MD, MRCS; Mohamed Elnagar MD ,MRCS. \\ Department of General Surgery, Ain Shams University, Cairo, Egypt.
}

Background: Total or complete rectal prolapse is the circumferential full-thickness protrusion of the rectal wall through the anus. Rectal prolapse is a major problem for both patients and surgeons. The aim of the treatment is to repair the prolapse and its complication (like incontinence) with minimal postoperative complication. Two approaches are generally possible to treat the patients; the perineal approach and abdominal approach, but both of them have many complications like obstructed defecation, fecal incontinence, and recurrence.

Since its invention, laparoscopic ventral rectopexy has many benefits for the patient, it is safe, effective, durable and minimally invasive. In this study, we evaluated the effect of Laparoscopic ventral rectopexy on fecal continence and postoperative morbidity (including constipation).

Aim of the study: Was to evaluate Laparoscopic ventral rectopexy for the treatment of rectal prolapse.

Patients and methods: This was a prospective study carried out at Ain Shams University Hospitals in Egypt and Saudi German Hospital in Jeddah, in the period between May 2011 and January 2015. Laparoscopic ventral rectopexy was performed in 28 consecutive patients who required surgery for total rectal prolapse. Follow-up was done for early postoperative complication, hospital stay, recurrence, severity of fecal incontinence, which was assessed by Wexner's incontinence score and the presence of constipation (obstructed defecation and STC) and its treatment (including laxative and enema use) which was assessed by Adapted Rome II Criteria over the interval (3,6 and 12 months) postoperative.

Results: There were 28 patients who underwent laparoscopic ventral rectopexy (24 female and 4 male) with mean age $55.6 \pm 5.3$ years. The average operating time range was $153 \pm 26$ min. There was no postoperative death and postoperative complications were minimal (one urinary tract infections \& two pelvic collections). The mean postoperative stay was 5.8 days. Two patients had recurred disease, and twelve of the 21 incontinent patients became fully continent; seven others experienced only a minor degree of incontinence. Before surgery, 13 patients with symptoms of constipation 9 of them improved after surgery.

Conclusion: Laparoscopic ventral rectopexy is an effective, minimally invasive procedure for the correction of rectal prolapse with minimal complications and lower recurrence rate.

Key words: Laparoscopic ventral rectopexy, rectal prolapse, obstructed defecation, slowtransit constipation.

\section{Introduction:}

Rectal procidentia, also called rectal prolapse, is a pelvic floor disorder that is an intussusception of the rectum extending beyond the anal canal that may lead to progressive anal sphincter damage and worsening incontinence Rectal prolapse results in local symptoms (eg, pain, bleeding, and seepage), bowel dysfunction (eg, constipation, incontinence), and a diminished and disabled quality of life. ${ }^{1}$

The true incidence of rectal prolapse is unknown, but it is thought to be uncommon. As most sufferers are elderly, the condition is generally under-reported. ${ }^{2}$ It may occur at any age, even in children, but there is peak 
onset in the fourth and seventh decades. ${ }^{2}$ Women over 50 are six times more likely to develop rectal prolapse than men. ${ }^{3}$ When males are affected, they tend to be young and report significant bowel function symptoms, especially obstructed defecation, or have a predisposing disorder (e.g., congenital anal atresia). $^{2}$

The purpose of surgery for rectal prolapse is to correct the prolapse itself and to protect or restore fecal continence. Unfortunately, postoperative constipation is the most common side-effect after mesh rectopexy and has been consistently reported in approximately half of the patients in large series. 4

An ideal surgical procedure for rectal prolapse would have low recurrence rates, low morbidity and provide some improvement in fecal incontinence. ${ }^{4}$

There are two approaches usually used to treat the patients. The perineal approach with the Delorme and the Altemeier procedures, but with a high rate of recurrence and mainly advised to patients not suitable for the abdominal approach. ${ }^{5}$ Since its first description by Orr in 1953 , and the modification introduced by Loygues in $1984,{ }^{6}$ the procedure of rectopexy has evolved through years and has become the procedure of choice in case of total rectal prolapse. There was little improvement, and in many cases, worsening of the symptoms that the procedure was aiming to relieve, namely obstructed defecation (OD) and fecal incontinence (FI). In addition to sigmoid resection mitigated these poor results to a degree, but at the expense of the potential risks of an anastomosis for benign disease. ${ }^{7}$

Laparoscopic ventral rectopexy may be associated with many benefits for the patient; it is safe, effective, durable, minimally invasive, autonomic nerve sparing and does not require colonic resection. Laparoscopic ventral rectopexy is resulting in less morbidity and a reduced hospital stay. ${ }^{8}$

In this study, we evaluated the effect of Laparoscopic ventral rectopexy on fecal continence and post-operative morbidity (including constipation).

\section{Patients and methods:}

This was a prospective study carried out at Ain Shams University Hospitals in Egypt and Saudi German Hospital in Jeddah, in the period between May 2011 and January 2015. Laparoscopic ventral rectopexy was performed in 28 consecutive patients who required surgery for total rectal prolapse.

Clinically, all patients had a full thickness external rectal prolapse. Preoperatively full blood tests were done including $\mathrm{CBC}$, liver function, urea and electrolytes and coagulation profile. Also, all patients underwent the anal ultrasound to exclude any rectal masses and the diagnosis was confirmed by defecation proctography. Fecal incontinence was assessed by Wexner's Incontinence Score Table (1). ${ }^{9}$

Patients were further subdivided using the Rome II criteria for constipation into four groups: Normal defecation, obstructed defecation, slow-transit constipation (STC), and combined obstructed defecation and STC Table (2). ${ }^{10}$ The same questionnaire and criteria were used to score postoperative functional outcome.

Any patient who has had a previous operation to rectal prolapse or left colon or rectum was excluded from the study.

Surgical technique: Laparoscopic ventral rectopexy with mesh:

Prophylactic antibiotics and prophylaxis against deep venous thrombosis are given. Mechanical bowel preparation is not needed and only rectal washout is performed under anesthesia to empty the lower rectum. The patient is placed in a lithotomy position.

Using a 4-port technique, the camera is placed through $10 \mathrm{~mm}$ port which is inserted at the umbilicus by Hasson's technique and 5-mm Trocars are inserted in the left and right iliac areas at the midaxillary lines. A 12-mm trocar is placed in the suprapubic area just to the right of midline. Trendelenburg position is used to expose the pelvic organs, and the small bowel is retracted cephalically.

Hysteropexy may be performed as needed for more exposure. The rectosigmoid is retracted toward the left upper quadrant to expose the peritoneum. The right ureter is 


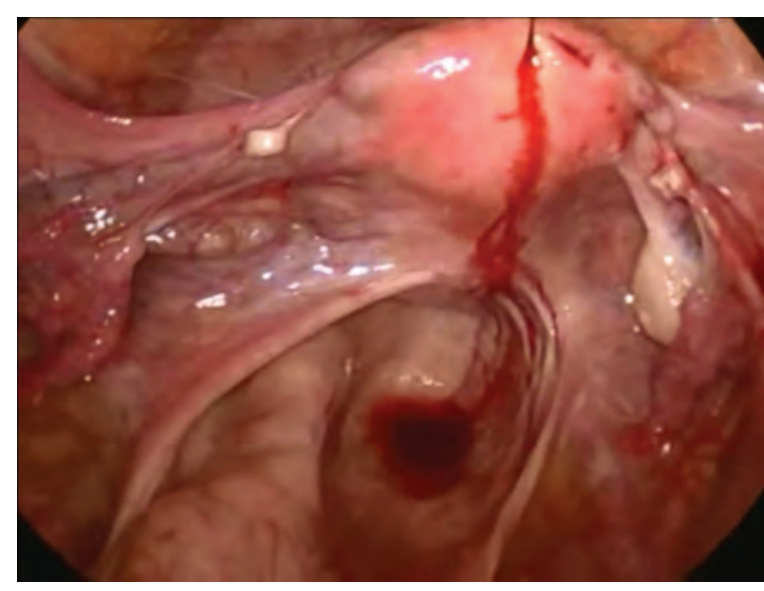

Figure (1): Hysteropexy for exposure of the field.

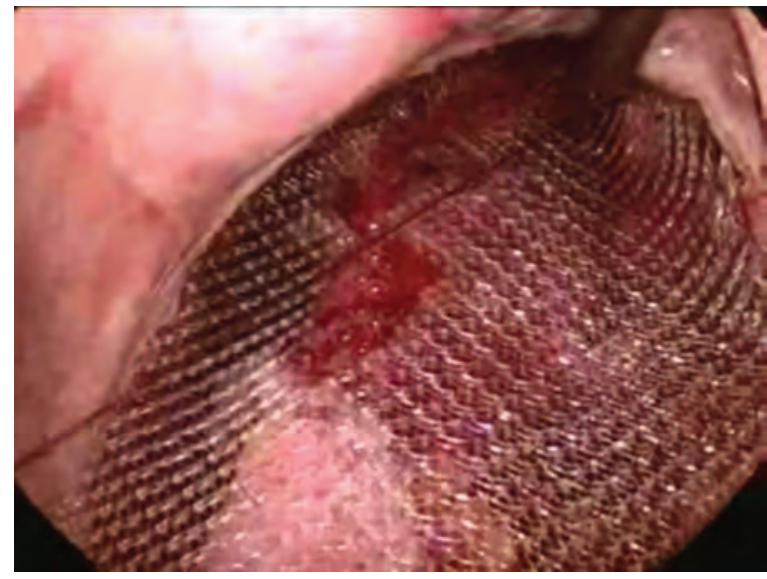

Figure (3): Insertion of the mesh.

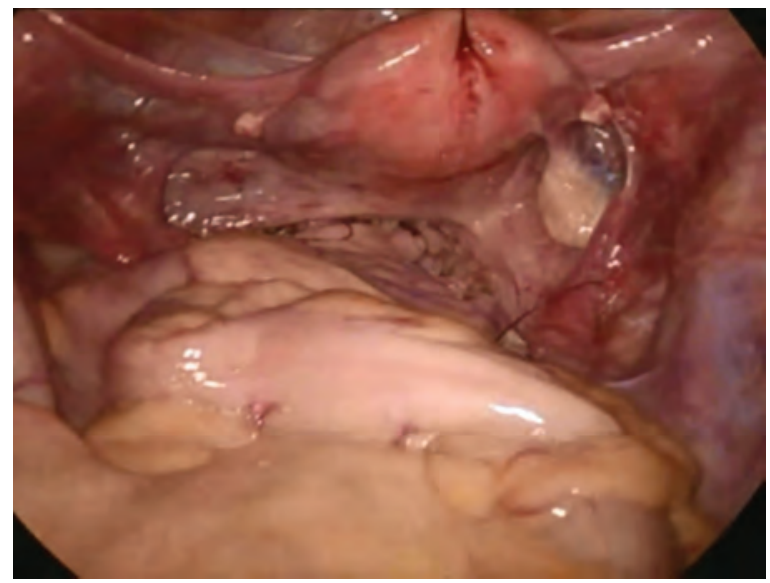

Figure (5): Closure of Douglas pouch.

identified along the right side of the pelvic wall. The right-side peritoneum is then incised at the level of the sacral promontory and the peritoneum is dissected downward in the midway between the rectum and sidewall to the level of the pelvic floor. By using dilators in the vagina and rectum, the rectovaginal septum is opened and the peritoneum over

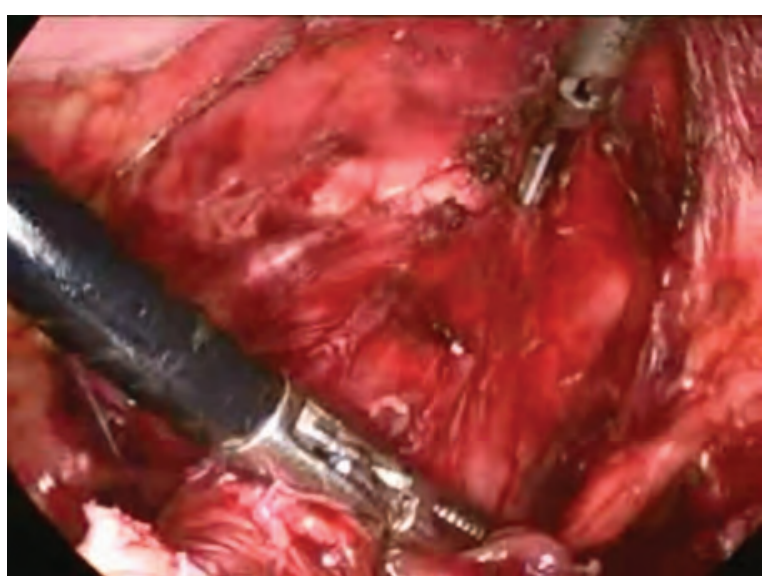

Figure (2): Dissection of the rectum.

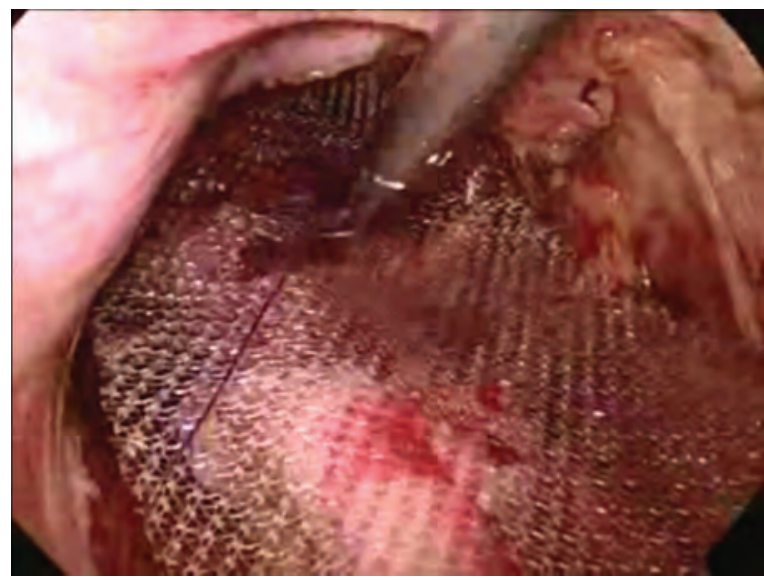

Figure (4): Fixation of the mesh.

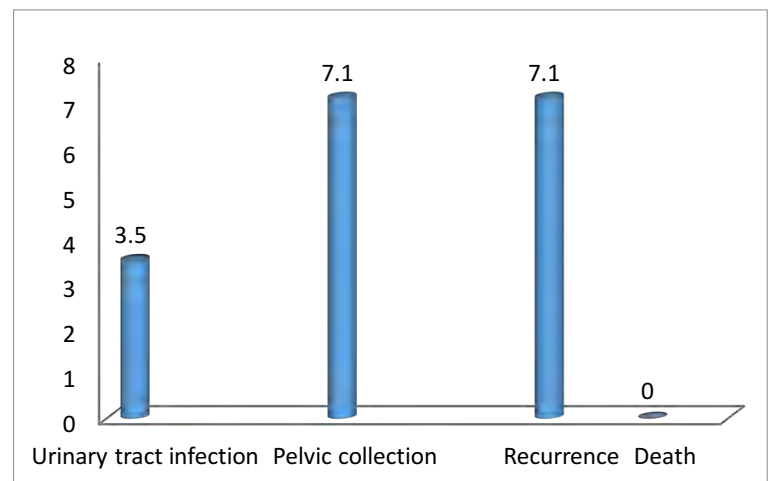

Figure (6): Distribution of postoperative complications in the study.

the Douglas pouch is excised to expose the anterior rectum.

If there is a symptomatic rectocele or perineal descent, the dissection can be continued down to the Perineal body and pubococcygeus muscles for more support. Polypropylene mesh measuring $\sim 7 \times 15 \mathrm{~cm}$ is introduced through the $12-\mathrm{mm}$ trocar site. 

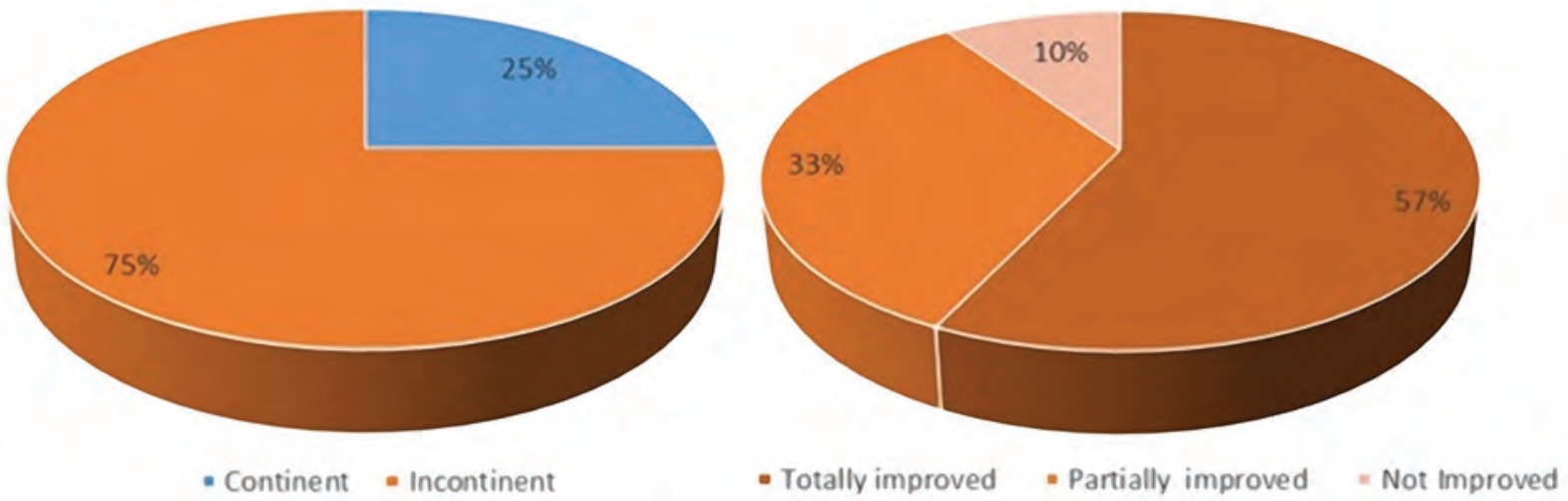

Figure (7): Charts of the effect of operation on continence in the study.

Preoperative

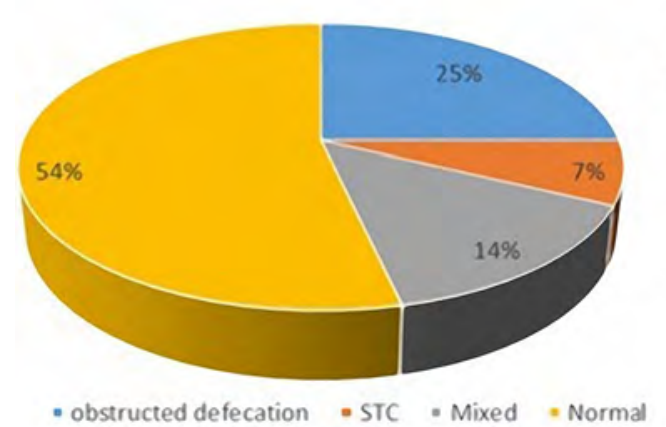

Effect on conestipation

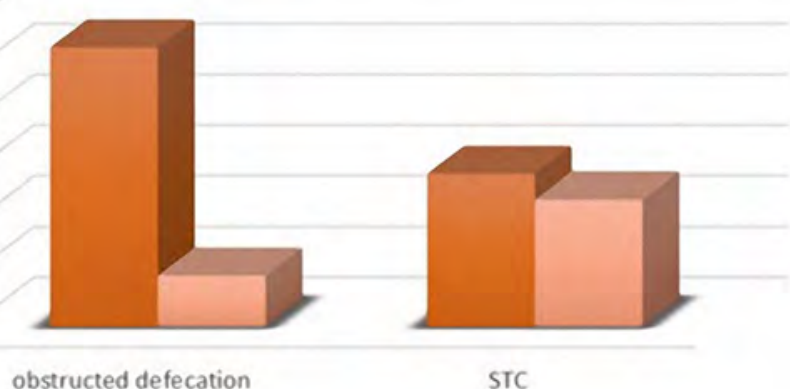

obstructed defecation

STC

- Preoperative =Postoperative

Figure (8): Chart of effect of operation on constipation.

Table (1) Wexnerss Incontinence Score. ${ }^{9}$

\begin{tabular}{|l|l|l|l|l|l|}
\hline Type of Incontinence & Never & Rarely & Sometimes & Usually & Always \\
\hline Solid & 0 & 1 & 2 & 3 & 4 \\
\hline Liquid & 0 & 1 & 2 & 3 & 4 \\
\hline Gas & 0 & 1 & 2 & 3 & 4 \\
\hline Wear Pad & 0 & 1 & 2 & 3 & 4 \\
\hline Lifestyle altered & 0 & 1 & 2 & 3 & 4 \\
\hline
\end{tabular}

\section{Never - 0}

Rarely - Less than once a month

Sometimes - Less than once a week or once a month

Usually - Once a day or once a week

Always - Once a day or more
SCORE: 0 PERFECT

20 COMPLETE INCONTINENCE
We use 2-0 polydioxanone (PDS) suture to secure the mesh laterally to the pelvic floor muscle, and the anterior rectal wall using six to eight laparoscopic sutures. Full-thickness rectal bites should be avoided. The sacral anterior lateral ligament is exposed at the sacral promontory and two laparoscopic sutures can be used to secure the mesh to 
Table 2: Functional Constipation (Rome II Criteria). ${ }^{9}$

\begin{tabular}{|l|}
\hline $\begin{array}{l}\text { Functional Constipation (Rome II criteria) } \\
\text { At least } 12 \text { weeks, which need not be consecutive, in the preceding } 12 \text { months of two or } \\
\text { more of: }\end{array}$ \\
\hline 1. Straining $>1 / 4$ of defecations; \\
\hline 2. Sensation of incomplete evacuation $>1 / 4$ of defecations \\
\hline 3. Sensation of anorectal obstruction/blockage $>1 / 4$ of defecations \\
\hline $\begin{array}{l}\text { 4. } \text { Manual maneuvers to facilitate }>1 / 4 \text { of defecations (e.g., digital evacuation, support of } \\
\text { the pelvic floor) }\end{array}$ \\
\hline 5. Lumpy or hard stools $>1 / 4$ of defecations; and/or \\
\hline 6. $<3$ defecations per week. \\
\hline (1-4 Obstructed defecation), ( 5-6 Slow-transit constipation STC)
\end{tabular}

Table 3: Patient demographics and operative time.

\begin{tabular}{|l|l|}
\hline Mean age & $55.6 \pm 5.3$ years (range $39-72)$ \\
\hline Male : Female & $4: 24$ \\
\hline Average operating time & $153 \pm 26$ minutes (153 to $197 \mathrm{~min}$ ) \\
\hline
\end{tabular}

Table (4): Changes in the continence post operatively.

\begin{tabular}{|l|l|l|l|c|}
\hline \multicolumn{1}{|c|}{ Variables } & \multicolumn{1}{|c|}{ No } & \multicolumn{1}{|c|}{$\%$} & Chi-square & P \\
\hline Preopartive (incontinent) & 21 & $75 \%$ & & \\
\cline { 1 - 3 } Postoperative & & & \\
\cline { 1 - 3 } Totally improved & 12 & $57.7 \%$ & \multirow{2}{*}{$0.02 \quad$ (S) } \\
\cline { 1 - 3 } Partially improved & 7 & $33.3 \%$ & & \\
\cline { 1 - 3 } Not Improved & 2 & $9.5 \%$ & & \\
\hline
\end{tabular}

the sacrum. The rectum should not be under tension. The peritoneum is closed over the mesh Figures (1-5).

\section{Follow-up:}

Follow up was done for early postoperative complication, hospital stay, recurrence, severity of fecal incontinence, which was assessed by Wexner's incontinence score and presence of constipation (obstructed defecation and STC) and its treatment (including laxative and enema use) which was assessed by Adapted Rome II criteria over the interval (3,6 and 12 months) postoperative.

Statistical analysis:

Analysis of data was done by IBM computer using SPSS (statistical program for social science version 16) as follows:
Description of quantitative variables as mean, SD and range, description of qualitative variables as number and percentage, Chisquare test was used to compare matched pairs before and after intervention. $\mathrm{P}$ value $>0.05$ was considered insignificant, $\mathrm{P}<0.05$ was considered significant,

$\mathrm{P}<0.001$ was considered highly significant.

\section{Results:}

28 patients underwent laparoscopic ventral rectopexy during our study. 24 (85.7\%) of them were females and $4(14.3 \%)$ were males. The mean age of the study group was $55.6 \pm 5.3$ years (range $39-72$ ). The average operating time was153 \pm 26 minutes (153 to 197 min) Table (3). 
Early postoperative course:

The mean hospital stay period was $5.8 \pm 1.6$ (range 2-10) days. There were no operation related mortality in the study. The early postoperative complication rate was $10.7 \%$ (three cases: One case of urinary tract infections \& two cases of pelvic collection). No patients were readmitted for surgical complications after the operation.

\section{Long-term outcome:}

Two patients (7.1\%) had recurrence, one of them had partial rectal prolapse due to large haemorrhoids and was treated with stapler hemorrhoidectomy. The other one has complete rectal prolapse and was treated with open resection rectopexy.

Before operation, 7 (25\%) patients were continent \& 21 (75\%) patients had variable degrees of incontinence. No effect was noted in continent patients. In 19 of 21 incontinent patients the continence improved. Twelve of the incontinent patients (57.1\%) became fully continent; seven (33.3\%) had only a minor degree of incontinence and in two patients (9.6\%) the incontinence did not improve. A statistically significant difference was found in the state of continence before and after the operation as shown in Table (4).

Thirteen patients had constipation before surgery (7 patients with obstructed defecation, two patients with STC and four patients with mixed constipation). A minor effect on STC was noted: Only one of six patients has improved (16.7\%). On the other hand, symptoms of obstructed defecation totally improved in 9 of 11 patients (81.8\%). No sever constipation of new onset was observed and constipation did not worsen in any patient.

\section{Discussion:}

Rectal prolapse is a major problem for both patients and surgeons. The aim of the treatment is to repair the prolapse and its complication like incontinence with minimal post operative complication like recurrence or constipation. ${ }^{11}$

There are two main categories of operation either abdominal or perineal. In general, the abdominal operations are more effective with lower recurrence. Posterior rectopexy with mesh is most common operation. ${ }^{12}$ The others points, like restoration or preservation of continence and the incidence of postoperative constipation, become important in determining an optimal procedure.

The recurrence rates after rectopexy range from zero to 16 percent and mainly reflect differences in technique and length of followup. ${ }^{13}$ In our study recurrence occurred in two of 28 (7.1\%).

Postoperative fecal incontinence is a significant problem after abdominal rectopexy. Preservation of the rectal reservoir seems to be important in providing the best chances of maintaining or regaining fecal continence. In perineal operations like Delorme mucosectomy the main problem is incontinence due to a reduction in the maximum tolerated rectal volume and rectal compliance, ${ }^{12}$ in our study the incontinent patients improved 12 of 21 totally improved with no effect on already continent patients.

Postoperative constipation occurs in up to half of all patients following abdominal rectopexy without sigmoidectomy. Various mechanisms are likely to contribute to this phenomenon. A redundant or kinking sigmoid may fold over the rectal fixation and delay transit. An increase in rectal wall thickness secondary to the rectal mobilization could alter the passage of stool to the lower rectum. The rectosigmoid is innervated from the sacral outflow (S2-S4), and deep lateral (anterolateral) dissection is likely to interfere with extrinsic sympathetic innervation. Full mobilization of the rectum may cause autonomic nerve damage and result in disturbed rectosigmoid motility. ${ }^{14}$

In ventral rectopexy the dissection is mainly anteriorly with no posterolateral mobilization so it will not affect the autonomic nerve also no increase in rectal wall thickness. In our study, no constipation happened after the operation in non constipated patients (15 patients), more than that, symptoms of obstructed defecation resolved in 9 of 11 patients.

The ventral position of the mesh is safe. 
Mesh erosion or pelvic sepsis has not been observed. Furthermore, the position of the mesh allows reinforcement of the rectovaginal septum and could, in part, explain the beneficial effect on symptoms of obstructed defecation. Also, the limited use of mesh and the position of the mesh on the anterior aspect of the rectum leaves Denonvillier's fascia intact. The avoidance of posterior dissection with fixation of the mesh to the sacral promontory rather than the presacral fascia prevents sever hemorrhage that may happen with injury of presacral venous plexus. ${ }^{15}$

\section{Conclusion:}

Laparoscopic ventral rectopexy is an effective, minimally invasive procedure for the correction of rectal prolapse. It appears to be as effective as classical rectopexy in terms of the recurrence rate and improvement of incontinence. Most importantly, it improves constipation without inducing new severe constipation and without the need for resection mainly due to the avoidance of rectal mobilization, and the relief of symptoms of obstructed defecation may be attributed to the ventral position of the mesh.

\section{Reference:}

1- Wijffels NA, Collinson R, Cunningham C, Lindsey I: What is the natural history of internal rectal prolapse? Colorectal Dis 2010; 12(8): 822-830.

2- Kairaluoma MV, Kellokumpu IH: Epidemiologic aspects of complete rectal prolapse. Scand J Surg 2005; 94(3): 207-210.

3- Gonzalez-Argente FX, Jain A, Nogueras JJ, Davila GW, Weiss EG, Wexner SD: Prevalence and severity of urinary incontinence and pelvic genital prolapse in females with anal incontinence and rectal prolapse. Dis Colon Rectum 2001; 44: 920-926.

4- Kuijpers HC: Treatment of complete rectal prolapse: To narrow, to wrap, to suspend, to fix, to encircle, to plicate or to resect? World $J$ Surg 1992; 16: 826-830.

5- Lieberth M, Kondylis LA, Reilly JC, Kondylis PD: The Delorme repair for full-thickness rectal prolapse: A retrospective review. Am J Surg 2009; 197: 418-423.

6- Loygue J, Nordlinger B, Cunci O, Malafosse M, Huguet C, Parc R: Rectopexy to the promontory for the treatment of rectal prolapse: Report of 257 cases. Dis Colon Rectum 1984; 27: 356-359 [PMID: 6376001 DOI: 10.1007/BF02552998]

7- Schiedeck TH, Schwandner O, Scheele J, Farke S, Bruch HP: Rectal prolapse: Which surgical option is appropriate? Langenbecks Arch Surg 2005; 390: 8-14.

8- Sajid M, Siddiqui M, Baig M: Open versus laparoscopic repair of full thickness rectal prolapse: A re-meta-analysis. Colorectal Dis 2009; 13.

9- Wexner SD, Marchetti F, Salanga VD, Corredor C, Jagelman DG: Neurophysiologic assessment of the anal sphincters. Dis Colon Rectum 1991; 34: 606-612.

10- Thompson WG, Longstreth GF, Drossman DA, Heaton KW, Irvine EJ, Muller-Lissner SA: Functional bowel disorders and functional abdominal pain. Gut 1999; 45(Suppl II): 1143-1147.

11- Madiba TE, Baig MK, Wexner SD: Surgical management of rectal prolapse. Arch Surg 2005; 140: 63-73.

12- Penninckx F, d'Hoore A, Sohier S, Kerremans $\mathrm{R}$ : Abdominal rectopexy versus Delorme's procedure for rectal prolapse: A predictable outcome. Int J Colorectal Dis 1996; 12: 49-50.

13- Eu KW, Seow-Choen F: Functional problems in adult rectal prolapse and controversies in surgical treatment. Br J Surg 1997; 84: 904-911.

14- Senapati A, Gray RG, Middleton LJ, Harding J, Hills RK, Armitage NC, et al: PROSPER: A randomized comparison of surgical treatments for rectal prolapse. Colorectal Dis 2013; 5.

15- Jean-Luc F, Bertrand T, Girard E, et al: Anterior rectopexy for full-thickness rectal prolapse: Technical and functional results. World $J$ Gastroenterol 2015; 21(16): 5049-5055. 